\title{
Older HIV-infected patients on antiretroviral therapy have B-cell expansion and attenuated CD4 cell increases with immune activation reduction
}

\author{
Robert C. Kalayjian ${ }^{\mathrm{a}}$, John Spritzler ${ }^{\mathrm{b}}$, Roy M. Matining ${ }^{\mathrm{b}}$, Susan A. Fiscus ${ }^{\mathrm{c}}$, Barry H. Gross ${ }^{\mathrm{d}}$, \\ Isaac R. Francis ${ }^{\mathrm{d}}$, Richard B. Pollard ${ }^{\mathrm{e}}$, Michael M. Lederman ${ }^{\dagger}$, and Alan Landay ${ }^{\mathrm{g}}$ \\ aMetroHealth Medical Center, Cleveland, Ohio \\ bHarvard School of Public Health, Boston, Massachusetts \\ 'University of North Carolina School of Medicine, Chapel Hill, North Carolina \\ dUniversity of Michigan, Ann Arbor, Michigan \\ eUniversity of California Davis, Sacramento, California \\ ${ }^{f}$ Case Western Reserve University School of Medicine, Cleveland, Ohio \\ gRush University School of Medicine, Chicago, Illinois, USA
}

\begin{abstract}
Background-The contribution of immune activation to accelerated HIV-disease progression in older individuals has not been delineated.

Methods-Prospective multicenter cohort of older ( $₫ 45$ years) and younger (18-30 years) HIVinfected adults initiating 192 weeks of antiretroviral therapy (ART). Longitudinal models of CD4 cell restoration examined associations with age-group, thymic volume, immune activation, and viral load.
\end{abstract}

\begin{abstract}
Results-Forty-five older and 45 younger adults (median age 50 and 26 years, respectively) were studied. Older patients had fewer naive CD4 cells $(P<0.001)$ and higher HLA-DR/CD38 expression on CD4 $(P=0.05)$ and CD8 cells $(P=0.07)$ than younger patients at any time on ART. The rate of naive and total CD4 cell increase was similar between age groups, but older patients had a faster mean rate of B-cell increase (by +0.7 cells/week; $P=0.01$ ), to higher counts than healthy controls after 192 weeks $(P=0.003)$. Naive CD4 increases from baseline were associated with immune activation reductions (as declines from baseline of \%CD8 cells expressing HLA-DR/ CD38; $P<0.0001$ ), but these increases were attenuated in older patients, or in those with small thymuses. A $15 \%$ reduction in activation was associated with naive gains of 29.9 and 6.2 cells $/ \mu \mathrm{l}$ in younger, versus older patients, or with gains of $25.7,23.4$, and 2.1 cells/ $\mu \mathrm{l}$ in patients with the
\end{abstract}

\footnotetext{
(C) 2013 Wolters Kluwer Health | Lippincott Williams \& Wilkins

Correspondence to Robert Charles Kalayjian, MD, MetroHealth Med Ctr, Cleveland, USA. rkalayjian@metrohealth.org.

Author's contributions: R.C.K.: conception and design, study implementation and patient enrollment, statistical analysis, draft of manuscript and revision, final approval; J.S.: conception and design, statistical analysis, revision of manuscript, final approval;

R.M.M.: conception and design, statistical analysis, revision of manuscript, final approval; S.F.: conception and design, acquisition of data, final approval; B.F.G.: conception and design, acquisition of data, final approval; I.R.F.: conception and design, acquisition of data, final approval; R.B.P.: conception and design, final approval; M.M.L.: conception and design, study implementation and patient enrollment, revision of manuscript, final approval; A.L.: conception and design, revision of manuscript, final approval.

Conflicts of interest

R.C.K., J.S., R.M.M., M.M.L., R.B.P., B.F.G., and I.R.F. and A.L. list none.

S.A.F. is a consultant for ViiV Healthcare end GenProbe.
} 
largest, intermediate, and smallest thymuses, respectively $(P<0.01$ for interactions between activation reduction and age-group or thymic volume).

Conclusion-Older patients had significant B-cell expansion, higher levels of immune activation markers, and significantly attenuated naive CD4 cell gains associated with activation reduction.

\section{Keywords}

aging; immune activation; immunosenescence; thymus

\section{Introduction}

Older age at the time of HIV-1 infection is a strong predictor of accelerated HIV disease progression in the absence of antiretroviral therapy (ART) [1], and older age ( $>45$ years) upon ART initiation is an independent predictor of AIDS or death [2-5]. Older adults (age >50) have a reduced capacity to restore naive and total CD4 cells with ART, despite often better adherence [6-8], and superior HIV-1 viral load suppression compared to younger individuals $[6,9,10]$. Older persons also have reduced thymopoiesis [11-13], and they are more likely to present for initial HIV care with lower CD4 cell counts, and each of these is associated with reduced capacity to restore CD4 cells [14-17].

Immune activation is thought central to HIV disease pathogenesis $[18,19]$. It is associated with reduced CD4 cell restoration on ART [20-22], and with increased morbidity and mortality, both in HIV disease and in the general population [23-25]. Contributions of immune activation to reduced CD4 cell restoration in older persons have not been delineated.

ACTG 5015 is a prospective multicenter cohort study of older (age $\geq 45$ years) and younger (age 18-30 years) ART-naive adults, to explore the immunologic basis of age-associated accelerated HIV disease progression. Participants began a uniform ART regimen and underwent intensive immunologic monitoring. Baseline and week 48 observations from this cohort were previously reported [26,27].

We hypothesized that differences in immune activation contribute to reduced CD4 cell restoration capacity in older HIV-infected individuals on ART. To test this hypothesis we examined age-associated differences of activation markers [\%CD8 cells that express HLADR/CD38, and soluble plasma tumor necrosis factor receptor (sTNFR)-2], which we compared with simultaneously enrolled, age-matched healthy controls (ACTG 5113). Independent contributions of age group, thymic volume, immune activation (as changes in $\% \mathrm{CD} 8$ cells that expressed HLA-DR/CD38), and viral load suppression were explored in longitudinal linear models of naive, memory, and total CD4 cell changes from baseline on ART.

\section{Methods}

ACTG 5015 is a multicenter, prospective study of older ( $\geq 45$ years) and younger (18-30 years) HIV-1-infected, ART-naive adults who enrolled between 2000 and 2004. All participants began stavudine, emtricitabine, and lopinavir/ritonaivir, and were followed up to 192 weeks. New diagnoses of hypertension, diabetes, and cardiovascular events (myocardial infarction, angina, congestive heart failure, peripheral vascular disease) were prespecified. Observations from patients who permanently discontinued ART, or who initiated chemotherapy, or prednisone were censored. The institutional review boards at each site approved this study, and all participants gave written informed consent to participate. 


\section{Virologic and immunologic studies}

Lymphocyte subsets were enumerated in freshly obtained whole blood by three-color flow cytometry using the AACTG consensus immunology protocol [28]; naive cells were defined as $\mathrm{CD} 45 \mathrm{RA}^{+} / \mathrm{CD} 2 \mathrm{~L}^{+}$; memory cells were $\mathrm{CD} 45 \mathrm{RO}^{+} / \mathrm{CD} 45 \mathrm{RA}^{-}$; $\mathrm{B}$ cells were $\mathrm{CD} 19^{+}$and natural killer (NK) cells were $\mathrm{CD} 3^{-} / \mathrm{CD} 16^{+} / \mathrm{CD} 56^{+}$.

The first 55 patients participated in an immunology substudy (ACTG 5016s) that also included thymic volume measurements, plasma cytokines (TNF-a, sTNFR-2, interleukin-7), and vaccination with tetanus toxoid (Aventis Pasteur, Swiftwater, Pennsylvania; LederlePraxis, West Henrietta, New York; or Wyeth-Ayerst, Philadelphia, Pennsylvania, USA) among all substudy participants, and hepatitis A vaccine (Smith-Kline Beecham, King of Prussia, Pennsylvania, USA), among hepatitis A antibody-negative participants at baseline and week 24. Age-matched healthy volunteers were simultaneously enrolled into ACTG study 5113 for cross-sectional comparisons. They underwent similar immunologic measurements, but received only one dose of each vaccine at baseline [26]. Serum antibodies to vaccine antigens were measured at baseline and week 12 for all participants, and also at week 36 for HIV-infected patients. Thymic volumes were estimated by noncontrast chest computed tomography (CT) scans at baseline, weeks 24 and 144, and scored on a scale of $0-5$, as previously described [12]. Scores were categorized within tertiles of approximately equal numbers of patients, defined as small (scores $0-1, n=18$ ), intermediate (score 2, $n=19$ ), and large (scores 3-5, $n=18$ ).

\section{Statistical analysis}

Cox proportional hazard models examined association between age group and time to viral load rebound among patients who achieved suppression to less than 200 copies $/ \mathrm{ml}$ within 24 weeks of ART initiation. Rebound was defined as a confirmed viral load above 200 copies/ $\mathrm{ml}$ after initial suppression. Age group differences of each immunologic index was assessed in separate mixed-effects models adjusted for sex, self-reported race (black, non-black), and time-varying viral loads; models of CD8 cell subsets, B cells, and cytokines were also adjusted for baseline CD4 cell counts.

Mixed-effects models of naive, memory, and total CD4 cell restoration examined associations with immune activation, thymic volume, and viral load replication. Covariate in these models either included age group or thymic volume, and included baseline viral load, time-varying viral load suppression (as viral load $<50,50$ to 1000 , and $\geq 1000$ copies $/ \mathrm{ml}$ ), and immune activation changes from baseline (as \%CD8 cells that expressed HLA-DR/ CD38). Immune activation changes were centered (each value was subtracted from the study population mean after 192 weeks, then divided by the SD). Models were adjusted for sex and race and they tested interactions between age group or thymic volume, with activation reduction and with viral load suppression. They assumed an autoregressive covariance structure and used random intercepts and random slopes.

The stratified (by sex) Wilcoxon Rank-Sum test was used to compare immune indices between HIV-infected patients and healthy controls within each age group, using the last protocol-specified measurement for HIV-infected patients; shift parameters and confidence intervals (CIs) were obtained by inverting this test. The generalized Cochran-MantelHaenszel test (also stratified by sex) compared week 48 thymic volume tertiles between HIV-infected patients and controls. Statistical significance was defined as $P$ less than 0.05 and no adjustment was made to account for multiple testing in these secondary, exploratory analyses. All analyses were performed using SAS (version 9.1; SAS Institute, Cary, North Carolina, USA). 


\section{Results}

\section{Age group differences in clinical and virologic outcomes in HIV-infected patients}

Fifty-nine (66\%) of 90 participants completed 192 weeks of follow-up, including 31 of 45 (69\%) older, and 28 of $45(62 \%)$ younger patients $(P=0.66)$. Older patients had more new cardiovascular events $(P=0.049)$, and tended to have more new diagnoses of diabetes $(P=$ $0.24)$, and AIDS-defining events or deaths $(P=0.14)$ (Table 1). There were no significant age group differences in the proportion of patients who achieved initial viral load suppression to below 200 copies $/ \mathrm{ml}$, but younger patients had a higher risk of viral load rebound after initial suppression [initial viral load suppression: 38 of $45(84 \%)$ older versus 37 of $45(82 \%)$ younger; rebound 6 older versus 16 younger; $P=0.02]$.

Thirty-one patients (17 younger and 14 older) prematurely withdrew from this study, among whom 16 younger, and seven older patients either were lost to follow-up, withdrew consent, or indicated that they were unable to return for study visits; one younger and seven older patients withdrew because they had met a prespecified indication for study discontinuation, were too debilitated to continue, or died. There was no statistically significant difference between age groups at the time to study discontinuation.

\section{Age group differences in the slopes of immunologic indices among HIV-infected patients}

Older HIV-infected patients had a significantly faster mean rate of B-cell increase [by +0.7 cells/ $\mu \mathrm{l}$ per week of ART ( $95 \%$ CI $0.2-1.3$ cells/ $\mu$ l per week), $P=0.01$ ], and a significantly faster mean rate of increase in the \%CD4 cells that expressed CD28 [by $+0.04 \%$ per week (95\% CI 0.01-0.08\%), $P=0.009$ ] compared to younger patients (Fig. 1, Table 2 and Supplemental Table, http://links.lww.com/QAD/A322). Older patients also had a significantly slower rate of hepatitis A antibody increase after vaccination [by $-0.014 \mathrm{mIU} /$ $\mathrm{ml}$ per week ( -0.025 to $-0.002 \mathrm{mIU} / \mathrm{ml}$ per week), $P=0.02]$. There were no significant age group differences in the slopes of other immunologic indices.

\section{Age group differences in the main effects of immunologic indices among HIV-infected participants}

Older patients maintained significantly fewer naive and total CD4 cells $(P \leq 0.03)$, they had a trend towards fewer naive CD8 cells $(P=0.053)$, but they had more NK cells $(P=0.03)$ than younger patients, as determined by the main effects of age group in each model (where the main effect is an estimate of the vertical distance between two approximately parallel lines, henceforth described as the differences at any time on ART; Fig. 1, Table 2 and Supplemental Table, http://links.lww.com/QAD/A322). Older patients also had a significantly lower \%CD8 cells that expressed CD28 $(P=0.002)$ and significantly smaller thymuses $(P=0.001)$, while having significantly higher \%CD4 and \%CD8 cells that expressed CD95/Fas $(P<0.003)$, and a trend towards higher HLA-DR/CD38 expression on these cells $(P=0.054$ and 0.07 , respectively). Although plasma TNF-a concentrations (measured to week 48) did not differ between the age groups, plasma sTNFR-2 concentrations were significantly higher in older patients $(P=0.006)$.

\section{Comparisons between HIV-infected, and HIV-uninfected participants}

After 192 weeks of ART, older and younger HIV-infected patients both had significantly fewer total CD4 cells $(P \leq 0.02)$, significantly more naive, memory and total CD8 cells ( $P$ $<0.02)$, significantly higher \%CD4 and \%CD8 cells that expressed HLA-DR/CD38 ( $P$ $<0.001$ ) compared to age-matched, HIV-uninfected healthy controls (Fig. 1, Table 2 and Supplemental Table, http://links.lww.com/QAD/A322). HIV-infected patients in both age groups also had significantly lower tetanus antibody concentrations 12 weeks after the first vaccination (at weeks 0 ) than controls, and despite similar plasma TNF-a levels, they also 
had higher plasma sTNFR-2 concentrations after 48 weeks of ART $(P<0.001)$. After 192 weeks of ART, NK cell counts and the \%CD4 and \%CD8 cells that expressed CD95/Fas were similar between HIV-infected patients and controls in both age groups.

HIV-infected older, but not younger patients had significantly fewer naive $(P<0.001)$ and memory CD4 cells after 192 weeks $(P=0.04)$, significantly more B cells $(P=0.003)$, and significantly higher hepatitis A antibody concentrations than their corresponding agematched controls after the first vaccination $(P=0.01)$. In contrast, younger HIV-infected patients had significantly lower \%CD4 and \%CD8 cells that expressed CD28 compared to controls after 192 weeks $(P \leq 0.01)$, whereas these differences were reduced to trends among older patients ( $P=0.07$ and $P=0.06$ for $\% \mathrm{CD} 4$ and $\% \mathrm{CD} 8$ cells, respectively). Younger HIV-infected patients also had trends towards smaller thymuses (measured to week 144; $P=$ 0.09 ) and higher IL-7 plasma concentrations (measured to week $48 ; P=0.096$ ) than controls, but these indices did not differ significantly among older patients.

\section{Multivariable models of naive cell restoration on antiretroviral therapy, and antibody responses to vaccination}

In longitudinal models, the magnitude of naive CD4 cell increase from baseline was independently associated with time-varying viral load suppression (as <50, 50 to 1000, and $>1000$ copies $/ \mathrm{ml} ; P=0.02$ ), and with the magnitude of immune activation reduction (as time-varying changes from baseline in the \%CD8 cells that expressed HLA-DR/CD38; $P$ $<0.001)$. The latter association depended on age, however, so the naive cell increases associated with activation reduction were significantly attenuated in older patients (Table 3). A $15 \%$ reduction in activation was associated with naive CD4 increases from baseline of 29.9 cells $/ \mu \mathrm{l}$ in younger patients, versus 6.2 cells $/ \mu \mathrm{l}$ in older patients $(P<0.001$ for the interaction between activation reduction and age group). A similar interaction was evident when baseline thymic volume replaced age group, where this magnitude of activation reduction was associated with naive CD4 cell gains of 25.7, 23.4, and 2.1 cells $/ \mu \mathrm{l}$ in patients with the largest, intermediate, and smallest thymic volumes, respectively ( $P=0.007$ for the interaction between activation reduction and thymic volume).

Interactions with immune activation were evident when age was treated as a continuous variable (data not shown), and they persisted in models of naive CD4 cell restoration that were stratified by baseline CD4 cell counts ( $P=0.004$ and $P=0.03$ for interactions with thymic volumes in patients with $<200$, and $\geq 200$ baseline CD4 cell counts, respectively). Significant interactions with age group or thymic volume were not detected with associations between naive CD4 increases and viral load suppression $(P=0.35$ and $P=0.48$, respectively).

Memory CD4 cell changes were associated with immune activation reductions $(P=0.003)$, but not viral load suppression $(P=0.23)$, and significant interactions were evident between activation reduction and age group $(P=0.0002)$, but not between activation reduction and thymic volume $(P=0.20)$ in these models. Viral load suppression and activation reduction also were associated with total CD4 cell increases ( $P=0.004$ and $P<0.0001$, respectively), and interactions were detected between activation reduction and age group, or thymic volume ( $P=0.02$ and $P=0.06$, respectively) in these models.

\section{Discussion}

In this prospective, age-differentiated cohort study, older patients had fewer naive and total CD4 cells, higher plasma sTNFR-2 concentrations, and they had trends towards higher HLA-DR/CD38 expression on CD4 and CD8 cells compared to younger patients at any time on ART. Older patients also exhibited a faster average rate of B-cell increase on ART, to 
counts that were significantly higher than age-matched healthy controls despite similar rates of naive, memory, and total CD4 cell increases between the age groups, and they had more NK cells at any time on ART. Consistent with previous studies, reductions in immune activation (defined as changes in the \%CD8 cells expressing HLA-DR/CD38) were associated with naive, memory, and total CD4 cell increases [20,22], but these associated increases were significantly attenuated in older patients, or in those with small thymuses, extending previous observations from this cohort of a similar interaction in association with early naive CD4 cell changes on ART [27].

Interactions between age and immune activation may imply qualitative differences in CD4 cells, or thymic function according to age, including increased CD4 cell susceptibility to activation-induced cell death in older patients. Homeostatic proliferation is a process by which naive CD4 cells undergo post-thymic expansion while retaining most of their phenotypic and functional naive cell characteristics [29]. Younger HIV-infected adults on ART have higher co-expression of CD31, a marker of recent thymic emigration on naive CD4 cells, than older adults [13]. Although thymic volume by CT cannot distinguish thymopoietically active epithelial space from inactive perivascular space within the thymus [30], thymic volume measured this way has previously been associated with naive CD4 cell increases in ART-treated HIV-infected adults [31]. Further study is warranted to determine whether naive CD4 cell restoration via homeostatic, versus intrathymic production pathways of naive may account for the interactions that we observed between immune activation and thymic volume. It is also possible that these interactions may identify a general impairment of CD4 cell restoration capacity in older persons that is not specifically related to immune activation mechanisms since older patients also had lower CD4 cell responses associated with viral load suppression. Even though significant interactions were not detected between age group, or thymic volume in these associations with viral load suppression, insufficient statistical power could have accounted for our inability to detect such interactions.

Older patients had a significantly slower rate of hepatitis A antibody increase after vaccination, but unexpectedly they had higher hepatitis A antibody concentrations compared to healthy older controls after the first vaccination. Previous studies identified B-cell activation markers as predictors of AIDS-associated lymphomas, AIDS-defining infections, or death $[23,28,32]$, implicating possible contributions of B-cell activation to HIV-disease pathogenesis. Further study is warranted to better understand the implications of the ageassociated differences in B-cell expansion that we observed.

Common immune perturbations that are characteristic of both untreated HIV-disease and normal aging [33], combined with the premature incidence of some age-associated morbidities support a hypothesis of premature aging in HIV disease [34,35]. Included among these perturbations are reduced T-cell receptor repertoire via diminished thymic output with lower circulating naive T-cell counts $[12,36]$, expansion of senescent $\mathrm{CD}^{+} \mathrm{T}$ cells (defined by CD28 ${ }^{-} / \mathrm{CD}^{+} 7^{+}$) [37,38], and macrophage dysfunction [39]. Differences between HIV-infected patients and controls that were accentuated among younger patients in the present study included lower CD28 expression on CD8 cells, smaller thymuses, and higher plasma IL-7 levels that may indicate premature immunosenescence.

Older patients experienced more cardiovascular events in this cohort. Although these events were not independently adjudicated, they were collected prospectively according to protocol-specified definitions. Also consistent with several other studies, we previously reported that medication adherence was better in older patients, which may have accounted for the lower rate of viral load rebound that we observed in older patients [40]. 
A strength of this study was in the prospective, protocol-specified measurement of selected immunologic indices in association with a uniform ART regimen, among ART-naïve patients, that were compared with simultaneously enrolled, age-matched healthy controls. Consistent with observations from the North American-ACCORD where older persons had lower CD4 cell counts at first presentation for HIV care [17], we previously reported significantly lower baseline CD4 cell counts in older HIV-infected patients [26]. Because the age at HIV-1 infection is unknown, we cannot exclude bias by confounding from more advanced HIV disease to have influenced the age group differences in this study. Since interactions between immune activation and age also were evident in separate models of naive CD4 cell restoration that were stratified by baseline CD4 cell counts (as $<200$, and $\geq 200$ cells $/ \mu \mathrm{l}$ ), confounding by advanced HIV disease is unlikely to have influenced these interactions.

Although we previously reported no significant age group differences in grade 3 or 4 medication-associated toxicities [40], it is possible that stavudine use may have contributed to a greater risk of mitochondrial dysfunction in older patients since age is a strong risk factor for nucleoside analog-associated lipodystrophy [41], a complication that has been associated with reduced mitochondrial (mt)DNA content [42]. Previous studies have identified significant differences in mtDNA according to prior nucleoside analog exposure [43]. Differences between mtDNA haplogroups also were associated with the magnitude of CD4 restoration [44], and with differences in T-cell activation on ART (as CD38/HLA-DR expression on CD4 and CD8 cells) [45], implicating possible contributions by mitochondrial function to the association between $\mathrm{CD} 4$ cell restoration and immune activation.

Only $64 \%$ of participants completed 192 weeks of follow-up in this study and this high attrition rate reduced the power to detect age group differences. Despite similar dropout rates between the age groups, missing data from attrition are a potential source of bias as the reasons for study discontinuation appeared to differ between the age groups, with higher attrition due to illness among older patients. Finally, statistical significance for all comparisons was not adjusted for multiple testing, hence these comparisons should be considered exploratory.

In conclusion, older HIV-infected patients maintained higher levels of some immune activation markers, and they demonstrated significant B-cell expansion on ART. Age and thymic volume modified associations between immune activation and CD4 cell restoration, so older patients had significantly attenuated naive, memory and total CD4 cell increases in association with activation reduction, and naive cell gains that were associated with activation reduction also were attenuated in patients with small thymuses. These interactions may identify qualitative differences in CD4 cells or thymic function according to age that warrant further study.

\section{Supplementary Material}

Refer to Web version on PubMed Central for supplementary material.

\section{Acknowledgments}

Financial support: NIH AI-069501, AI-68634, AI-68636, AI-36219 and the Veterans Administration: VISN10 Geriatric Research Educational and Clinical Centers, Louis Stokes Cleveland Veterans Administration Medical Center. 


\section{References}

1. Collaborative Group on AIDS Incubation and HIV Survival including the CASCADE EU Concerted Action. Concerted Action on SeroConversion to AIDS and Death in Europe . Time from HIV-1 seroconversion to AIDS death before widespread use of highly-active antiretroviral therapy: a collaborative re-analysis. Lancet. 2000; 355:1131-1137. [PubMed: 10791375]

2. Egger M, May M, Chene G, Phillips AN, Ledergerber B, Dabis F, et al. Prognosis of HIV-1infected patients starting highly active antiretroviral therapy: a collaborative analysis of prospective studies. Lancet. 2002; 360:119-129. [PubMed: 12126821]

3. Grabar S, Kousignian I, Sobel A, Le Bras P, Gasnault J, Enel P, et al. Immunologic and clinical responses to highly active antiretroviral therapy over 50 years of age. Results from the French Hospital Database on HIV. AIDS. 2004; 18:2029-2038. [PubMed: 15577624]

4. Stringer JS, Zulu I, Levy J, Stringer EM, Mwango A, Chi BH, et al. Rapid scale-up of antiretroviral therapy at primary care sites in Zambia: feasibility and early outcomes. JAMA. 2006; 296:782-793. [PubMed: 16905784]

5. Kitahata MM, Gange SJ, Abraham AG, Merriman B, Saag MS, Justice AC, et al. Effect of early versus deferred antiretroviral therapy for HIV on survival. N Engl J Med. 2009; 360:1815-1826. [PubMed: 19339714]

6. Le Moing V, Chene G, Carrieri MP, Alioum A, Brun-Vezinet F, Piroth L, et al. Predictors of virological rebound in HIV-1-infected patients initiating a protease inhibitor-containing regimen. AIDS. 2002; 16:21-29. [PubMed: 11741159]

7. Hinkin CH, Hardy DJ, Mason KI, Castellon SA, Durvasula RS, Lam MN, et al. Medication adherence in HIV-infected adults: effect of patient age, cognitive status, and substance abuse. AIDS. 2004; 18 (Suppl 1):S19-S25. [PubMed: 15075494]

8. Paterson DL, Swindells S, Mohr J, Brester M, Vergis EN, Squier C, et al. Adherence to protease inhibitor therapy and outcomes in patients with HIV infection. Ann Intern Med. 2000; 133:21-30. [PubMed: 10877736]

9. Drusano GL, Bilello JA, Stein DS, Nessly M, Meibohm A, Emini EA, et al. Factors influencing the emergence of resistance to indinavir: role of virologic, immunologic, and pharmacologic variables. J Infect Dis. 1998; 178:360-367. [PubMed: 9697715]

10. Bosch RJ, Bennett K, Collier AC, Zackin R, Benson CA. Pre-treatment factors associated with 3year (144-week) virologic and immunologic responses to potent antiretroviral therapy. J Acquir Immune Defic Syndr. 2007; 44:268-277. [PubMed: 17146370]

11. Kolte L, Dreves AM, Ersboll AK, Strandberg C, Jeppesen DL, Nielsen JO, et al. Association between larger thymic size and higher thymic output in human immunodeficiency virus-infected patients receiving highly active antiretroviral therapy. J Infect Dis. 2002; 185:1578-1585. [PubMed: 12023763]

12. McCune JM, Loftus R, Schmidt DK, Carroll P, Webster D, Swor-Yim LB, et al. High prevalence of thymic tissue in adults with human immunodeficiency virus-1 infection. J Clin Invest. 1998; 101:2301-2308. [PubMed: 9616201]

13. Rickabaugh TM, Kilpatrick RD, Hultin LE, Hultin PM, Hausner MA, Sugar CA, et al. The dual impact of HIV-1 infection and aging on naive CD4 T-cells: additive and distinct patterns of impairment. PLoS One. 2011; 6:e16459. [PubMed: 21298072]

14. Dragsted UB, Mocroft A, Vella S, Viard JP, Hansen AB, Panos G, et al. Predictors of immunological failure after initial response to highly active antiretroviral therapy in HIV-1infected adults: a EuroSIDA study. J Infect Dis. 2004; 190:148-155. [PubMed: 15195254]

15. Robbins GK, Spritzler JG, Chan ES, Asmuth DM, Gandhi RT, Rodriguez BA, et al. Incomplete reconstitution of $\mathrm{T}$ cell subsets on combination antiretroviral therapy in the AIDS Clinical Trials Group protocol 384. Clin Infect Dis. 2009; 48:350-361. [PubMed: 19123865]

16. Spritzler J, Mildvan D, Russo A, Asthana D, Livnat D, Schock B, et al. Can immune markers predict subsequent discordance between immunologic and virologic responses to antiretroviral therapy? Adult AIDS Clinical Trials Group. Clin Infect Dis. 2003; 37:551-558. [PubMed: 12905140] 
17. Althoff KN, Gebo KA, Gange SJ, Klein MB, Brooks JT, Hogg RS, et al. CD4 count at presentation for HIV care in the United States and Canada: are those over 50 years more likely to have a delayed presentation? AIDS Res Ther. 2010; 7:45. [PubMed: 21159161]

18. Hazenberg MD, Otto SA, van Benthem BH, Roos MT, Coutinho RA, Lange JM, et al. Persistent immune activation in HIV-1 infection is associated with progression to AIDS. AIDS. 2003; 17:1881-1888. [PubMed: 12960820]

19. Sousa AE, Carneiro J, Meier-Schellersheim M, Grossman Z, Victorino RM. CD4 T cell depletion is linked directly to immune activation in the pathogenesis of HIV-1 and HIV-2 but only indirectly to the viral load. J Immunol. 2002; 169:3400-3406. [PubMed: 12218162]

20. Gandhi RT, Spritzler J, Chan E, Asmuth DM, Rodriguez B, Merigan TC, et al. Effect of baselineand treatment-related factors on immunologic recovery after initiation of antiretroviral therapy in HIV-1-positive subjects: results from ACTG 384. J Acquir Immune Defic Syndr. 2006; 42:426434. [PubMed: 16810109]

21. Hunt PW, Cao HL, Muzoora C, Ssewanyana I, Bennett J, Emenyonu N, et al. Impact of CD8+ Tcell activation on CD4+T-cell recovery and mortality in HIV-infected Ugandans initiating antiretroviral therapy. AIDS. 2011; 25:2123-2131. [PubMed: 21881481]

22. Hunt PW, Martin JN, Sinclair E, Bredt B, Hagos E, Lampiris H, et al. T cell activation is associated with lower CD4+ T cell gains in human immunodeficiency virus-infected patients with sustained viral suppression during antiretroviral therapy. J Infect Dis. 2003; 187:1534-1543. [PubMed: 12721933]

23. Kalayjian RC, Machekano RN, Rizk N, Robbins GK, Gandhi RT, Rodriguez BA, et al. Pretreatment levels of soluble cellular receptors and interleukin- 6 are associated with HIV disease progression in subjects treated with highly active antiretroviral therapy. J Infect Dis. 2010; 201:1796-1805. [PubMed: 20446847]

24. Zethelius B, Berglund L, Sundstrom J, Ingelsson E, Basu S, Larsson A, et al. Use of multiple biomarkers to improve the prediction of death from cardiovascular causes. N Engl J Med. 2008; 358:2107-2116. [PubMed: 18480203]

25. Kuller LH, Tracy R, Belloso W, De Wit S, Drummond F, Lane HC, et al. Inflammatory and coagulation biomarkers and mortality in patients with HIV infection. PLoS Med. 2008; 5:e203. [PubMed: 18942885]

26. Kalayjian RC, Landay A, Pollard RB, Taub DD, Gross BH, Francis IR, et al. Age-related immune dysfunction in health and in human immunodeficiency virus (HIV) disease: association of age and HIV infection with naive CD8+ cell depletion, reduced expression of CD28 on CD8+ cells, and reduced thymic volumes. J Infect Dis. 2003; 187:1924-1933. [PubMed: 12792869]

27. Kalayjian RC, Spritzler J, Pu M, Landay A, Pollard RB, Stocker V, et al. Distinct mechanisms of T cell reconstitution can be identified by estimating thymic volume in adult HIV-1 disease. J Infect Dis. 2005; 192:1577-1587. [PubMed: 16206072]

28. Widney D, Gundapp G, Said JW, van der Meijden M, Bonavida B, Demidem A, et al. Aberrant expression of CD27 and soluble CD27 (sCD27) in HIV infection and in AIDS-associated lymphoma. Clin Immunol. 1999; 93:114-123. [PubMed: 10527687]

29. Kohler S, Thiel A. Life after the thymus: CD31+ and CD31-human naive CD4+ T-cell subsets. Blood. 2009; 113:769-774. [PubMed: 18583570]

30. Flores KG, Li J, Sempowski GD, Haynes BF, Hale LP. Analysis of the human thymic perivascular space during aging. J Clin Invest. 1999; 104:1031-1039. [PubMed: 10525041]

31. Smith KY, Valdez H, Landay A, Spritzler J, Kessler HA, Connick E, et al. Thymic size and lymphocyte restoration in patients with human immunodeficiency virus infection after 48 weeks of zidovudine, lamivudine, and ritonavir therapy. J Infect Dis. 2000; 181:141-147. [PubMed: 10608760]

32. Regidor DL, Detels R, Breen EC, Widney DP, Jacobson LP, Palella F, et al. Effect of highly active antiretroviral therapy on biomarkers of B-lymphocyte activation and inflammation. AIDS. 2011; 25:303-314. [PubMed: 21192231]

33. Deeks SG. HIV infection, inflammation, immunosenescence, and aging. Annu Rev Med. 2011; 62:141-155. [PubMed: 21090961] 
34. Appay V, Rowland-Jones SL. Premature ageing of the immune system: the cause of AIDS? Trends Immunol. 2002; 23:580-585. [PubMed: 12464569]

35. Guaraldi G, Orlando G, Zona S, Menozzi M, Carli F, Garlassi E, et al. Premature age-related comorbidities among HIV-infected persons compared with the general population. Clin Infect Dis. 2011; 53:1120-1126. [PubMed: 21998278]

36. Roederer M, Dubs JG, Anderson MT, Raju PA, Herzenberg LA. CD8 naive T cell counts decrease progressively in HIV-infected adults. J Clin Invest. 1995; 95:2061-2066. [PubMed: 7738173]

37. Effros RB, Allsopp R, Chiu CP, Hausner MA, Hirji K, Wang L, et al. Shortened telomeres in the expanded CD28-CD8+ cell subset in HIV disease implicate replicative senescence in HIV pathogenesis. AIDS. 1996; 10:F17-F22. [PubMed: 8828735]

38. Tassiopoulos K, Landay A, Collier AC, Connick E, Deeks SG, Hunt P, et al. CD28-negative CD4+ and CD8+ T cells in antiretroviral therapy-naive HIV-infected adults enrolled in adult clinical trials group studies. J Infect Dis. 2012; 205:1730-1738. [PubMed: 22448010]

39. Hearps AC, Maisa A, Cheng WJ, Angelovich TA, Lichtfuss GF, Palmer CS, et al. HIV infection induces age-related changes to monocytes and innate immune activation in young men that persist despite combination antiretroviral therapy. AIDS. 2012; 26:843-853. [PubMed: 22313961]

40. Crawford KW, Spritzler J, Kalayjian RC, Parsons T, Landay A, Pollard R, et al. Age-related changes in plasma concentrations of the HIV protease inhibitor lopinavir. AIDS Res Hum Retroviruses. 2010; 26:635-643.

41. Mallal SA, John M, Moore CB, James IR, McKinnon EJ. Contribution of nucleoside analogue reverse transcriptase inhibitors to subcutaneous fat wasting in patients with HIV infection. AIDS. 2000; 14:1309-1316. [PubMed: 10930144]

42. Shikuma CM, Hu N, Milne C, Yost F, Waslien C, Shimizu S, et al. Mitochondrial DNA decrease in subcutaneous adipose tissue of HIV-infected individuals with peripheral lipoatrophy. AIDS. 2001; 15:1801-1809. [PubMed: 11579242]

43. Payne BA, Wilson IJ, Hateley CA, Horvath R, Santibanez-Koref M, Samuels DC, et al. Mitochondrial aging is accelerated by antiretroviral therapy through the clonal expansion of mtDNA mutations. Nat Genet. 2011; 43:806-810. [PubMed: 21706004]

44. Grady BJ, Samuels DC, Robbins GK, Selph D, Canter JA, Pollard RB, et al. Mitochondrial genomics and CD4 T-cell count recovery after antiretroviral therapy initiation in AIDS clinical trials group study 384. J Acquir Immune Defic Syndr. 2011; 58:363-370. [PubMed: 21792066]

45. Hulgan T, Robbins GK, Kalams SA, Samuels DC, Grady B, Shafer R, et al. T cell activation markers and African mitochondrial DNA haplogroups among non-Hispanic black participants in AIDS clinical trials group study 384. PLoS One. 2012; 7:e43803. [PubMed: 22970105] 

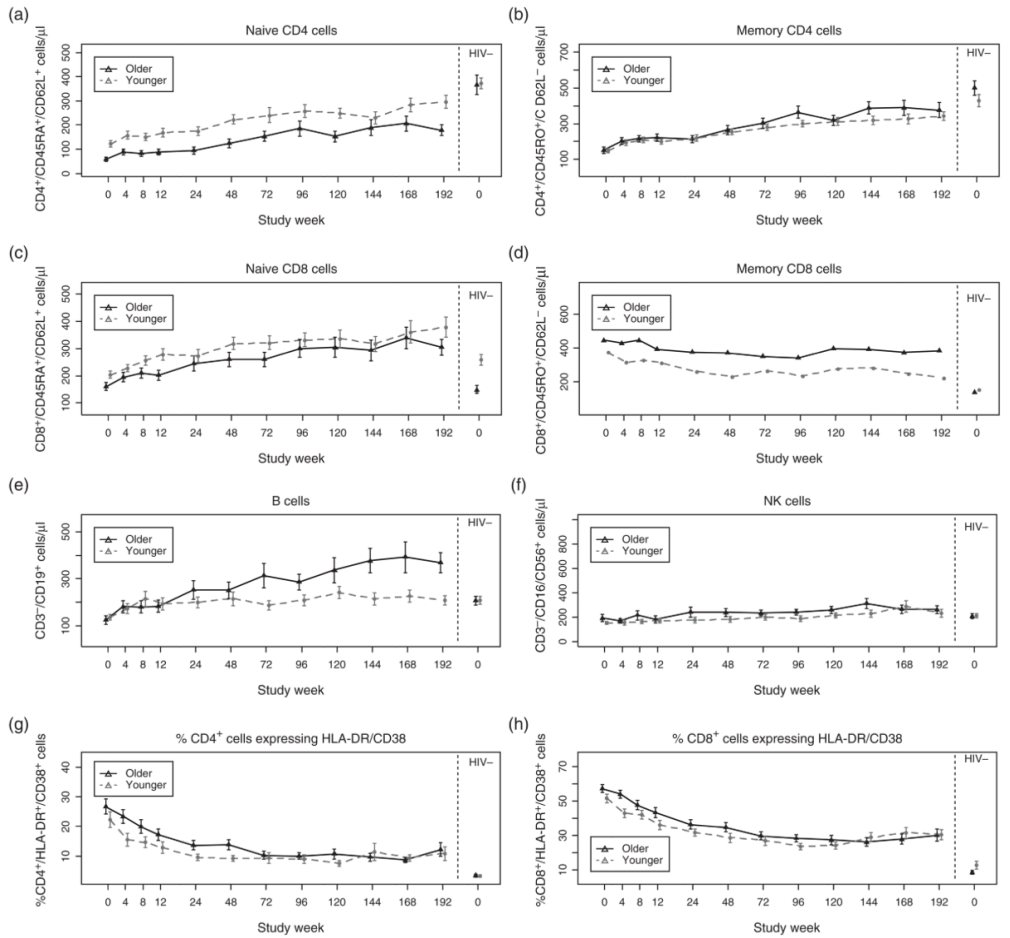

(i)
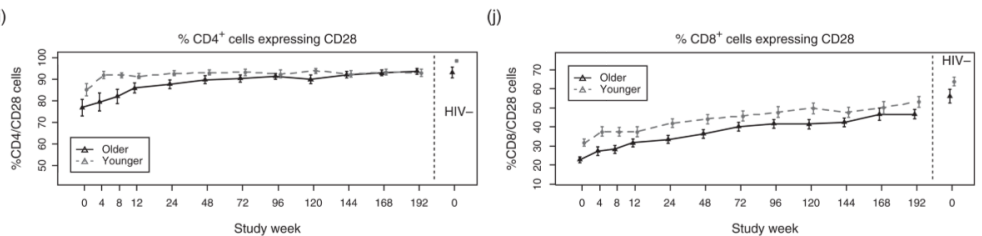

$(\mathrm{k})$
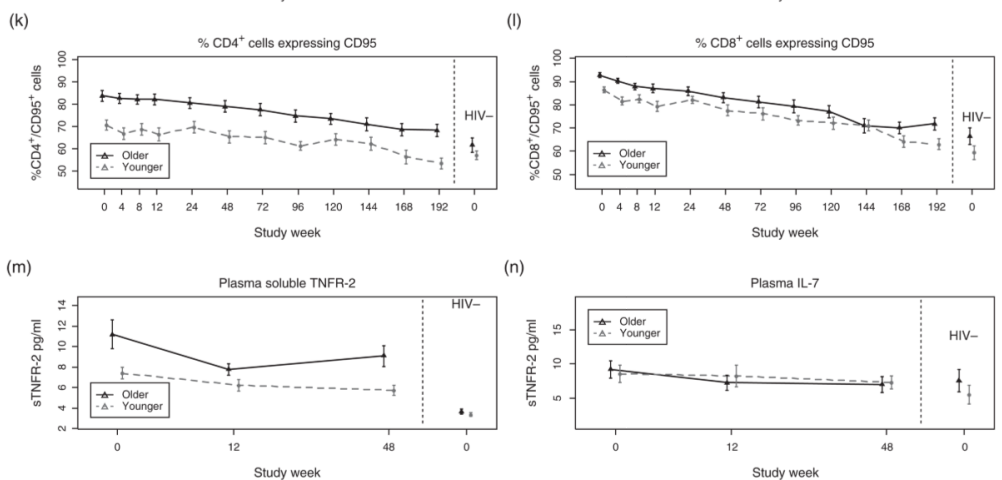

(n)
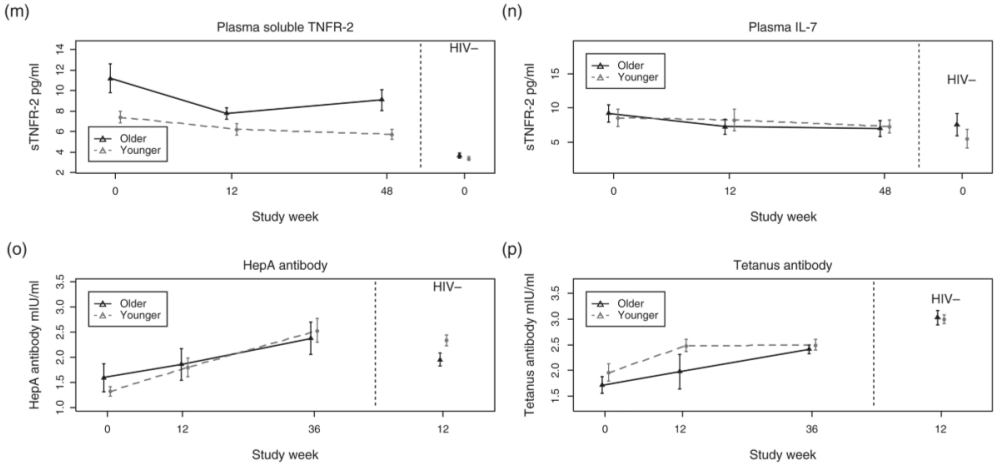

Fig. 1. Changes in immune indices with ART in older and younger subjects ( $a$ and b) Changes in mean naive and memory CD4 cell counts; (c and d) naive and memory $\mathrm{CD} 8$ cells, (e) B cells, (f) $\mathrm{NK}$ cells, (g and h) \%CD4 ${ }^{+}$and $\mathrm{CD} 8^{+}$cells expressing HLA-DR/ $\mathrm{CD} 38$ cells, $(\mathrm{i}$ and $\mathrm{j}) \% \mathrm{CD} 4^{+}$and $\mathrm{CD} 8^{+}$cells expressing $\mathrm{CD} 28$, $(\mathrm{k}$ and $\mathrm{l}) \% \mathrm{CD} 4^{+}$and $\mathrm{CD} 8^{+}$ cells expressing CD95, (m) soluble tumor necrosis receptor plasma concentration, (n) 
plasma interleukin 7 levels, and (o) hepatitis A and tetanus antibody concentrations after vaccination, in older (solid line) and young (broken line) over time among HIV-infected patients (left panels) compared with healthy HIV-uninfected controls (right panels). Vertical lines represent $1 \mathrm{SD}$ from the mean. 
Table 1

Serious adverse clinical events in older and young HIV-infected participants during 192 weeks of observation.

\begin{tabular}{|c|c|c|c|}
\hline \multirow[b]{2}{*}{ Clinical events } & \multicolumn{2}{|c|}{ Number of events } & \multirow[b]{2}{*}{$P$ value } \\
\hline & Older & Young & \\
\hline Cardiovascular & & & 0.049 \\
\hline Hypertension & 5 & 2 & \\
\hline Peripheral vascular disease & 2 & 0 & \\
\hline Heart disease & 2 & 0 & \\
\hline Total & 9 & 2 & \\
\hline Diabetes & 3 & 0 & 0.24 \\
\hline HIV-associated or death & & & 0.14 \\
\hline Pneumocystis jorovecci & 1 & 0 & \\
\hline Cryptococcal meningitis & 0 & 1 & \\
\hline Toxoplasmic encephalitis & 0 & 1 & \\
\hline AIDS wasting & 1 & 0 & \\
\hline Esophageal candidiasis & 1 & 1 & \\
\hline HIV-associated myelopathy & 1 & 0 & \\
\hline Non Hodgkin's lymphoma & 1 & 1 & \\
\hline HIV-associated nephropathy & 1 & 0 & \\
\hline Anogenital neoplasia & 1 & 0 & \\
\hline Other $^{a}$ & 1 & 0 & \\
\hline Death & 2 & 0 & \\
\hline Total & 10 & 4 & \\
\hline
\end{tabular}


Table 2

A summary of age group differences among HIV-infected patients and differences between HIV-infected patients and healthy controls.

\begin{tabular}{|c|c|c|c|c|}
\hline & \multicolumn{2}{|c|}{ HIV+: older versus younger } & \multicolumn{2}{|c|}{ HIV+ versus healthy control } \\
\hline & Baseline & Week 0 to 192 & Older & Younger \\
\hline Naive CD4 cells & $\downarrow$ & $\downarrow$ & $\downarrow$ & $\leftrightarrow$ \\
\hline Naive CD8 cells & $\downarrow$ & $w^{*}$ & $\uparrow$ & $\uparrow$ \\
\hline Memory CD4 cells & $\leftrightarrow$ & $\leftrightarrow$ & $\downarrow$ & $\leftrightarrow$ \\
\hline Memory CD8 cells & $\uparrow$ & 快 & $\uparrow$ & $\uparrow$ \\
\hline Total CD4 cells & $\downarrow$ & $\downarrow$ & $\downarrow$ & $\downarrow$ \\
\hline Total CD8 cells & $\leftrightarrow$ & $\leftrightarrow$ & $\uparrow$ & $\uparrow$ \\
\hline B cells & $\downarrow$ & $\Delta$ & $\uparrow$ & $\leftrightarrow$ \\
\hline NK cells & $\leftrightarrow$ & $\uparrow$ & $\leftrightarrow$ & $\leftrightarrow$ \\
\hline$\% \mathrm{CD} 4$ expressing $\mathrm{CD} 28$ & $*$ & $\boldsymbol{\Delta}$ & $*$ & $\downarrow$ \\
\hline$\% \mathrm{CD} 8$ expressing CD28 & $\downarrow$ & $\downarrow$ & $*$ & $\downarrow$ \\
\hline \%CD4 expressing HLA-DR/CD38 & $\leftrightarrow$ & 米 & $\uparrow$ & $\uparrow$ \\
\hline$\% \mathrm{CD} 8$ expressing HLA-DR/CD38 & $\leftrightarrow$ & 陆 & $\uparrow$ & $\uparrow$ \\
\hline$\% \mathrm{CD} 4$ expressing CD95 & $\uparrow$ & $\uparrow$ & $\leftrightarrow$ & $\leftrightarrow$ \\
\hline \%CD8 expressing CD95 & $\uparrow$ & $\uparrow$ & $\leftrightarrow$ & $\leftrightarrow$ \\
\hline TNF-a & $\leftrightarrow$ & $\leftrightarrow$ & $\leftrightarrow$ & $\leftrightarrow$ \\
\hline sTNFR-2 & $\uparrow$ & $\uparrow$ & $\uparrow$ & $\uparrow$ \\
\hline IL7 & $\leftrightarrow$ & $\leftrightarrow$ & $\leftrightarrow$ & 米 \\
\hline Thymic CT score & $\downarrow$ & $\downarrow$ & $\leftrightarrow$ & $*$ \\
\hline Vaccine response hepatitis A & & $\nabla$ & $\uparrow$ & $\leftrightarrow$ \\
\hline Vaccine response tetanus & & $\leftrightarrow$ & $\downarrow$ & $\downarrow$ \\
\hline
\end{tabular}

' $\boldsymbol{\Lambda}$ ' or ' $\boldsymbol{\nabla}$ ' identify significant slope differences $(P<0.05)$ between HIV-infected older and younger patients, by mixed-effects linear models; ' $\downarrow$ ' or ' $\uparrow$ identify significant differences $(P<0.05)$ in the main-effects of age-group, or differences between HIV-infected patients (at the last protocolspecified measurement on ART) and controls by shift parameters. Trends $(0.05 \leq P<0.10)$ are indicated by an '*', and ' $\leftrightarrow$ ' indicates no significant difference $(P \geq 0.10)$. Baseline age-group differences were previously reported. [26,27]. 


\section{Table 3}

Estimates of naive and memory CD4 cell increases from baseline in association with immune activation reduction (as time varying changes from baseline in $\% \mathrm{CD}^{+} / \mathrm{HLA}-\mathrm{DR}^{+} / \mathrm{CD} 38^{+}$cells) and viral load (VL) suppression (as time-varying plasma $\mathrm{VL}<50,5-0-1000$ and $>1000$ copies $/ \mathrm{ml}$ ), according to age groups or thymic volume tertiles (as thymic score: 0 to 1,2 , and $>2$, from CT estimates of thymic volume) from longitudinal mixed linear models that were adjusted for sex, and race (black, not black).

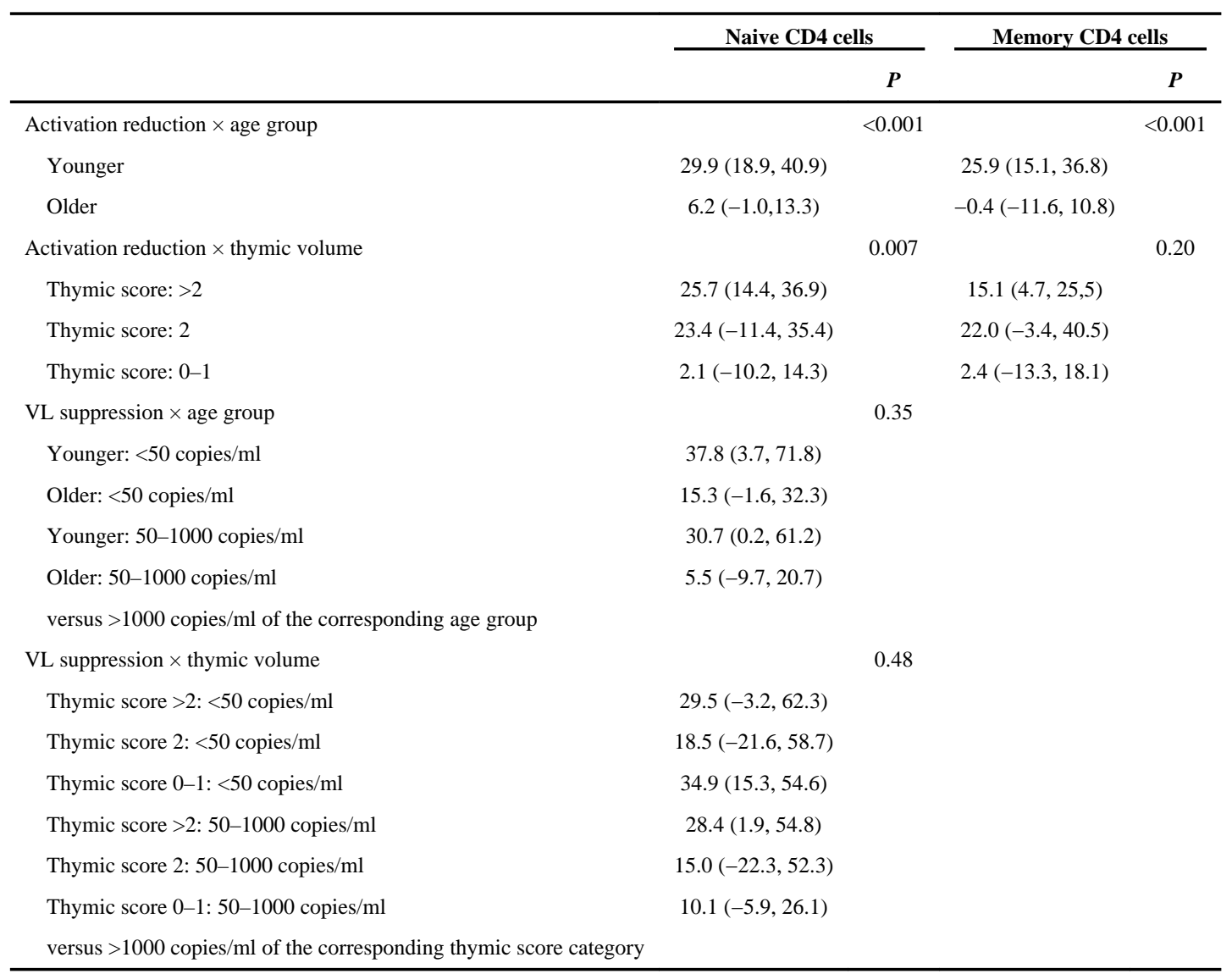

$P$-values report the significance of the interaction terms between age group or thymic volume, in the associations between immune activation or VL suppression with CD4 cell increases. Memory CD4 cell increases were not associated with VL suppression. 